\title{
Insights from birthing experiences of fistula survivors in North Central Nigeria: Interplay of structural violence
}

Obstetric Fistula is an abnormal opening between the vagina and rectum resulting from prolonged and obstructed labour. Studies indicate that delays in accessing maternal care and home birth contribute to the development of fistula. Survivors are usually women of low socioeconomic status residing in rural locations. This study explores the birthing experiences of 15 fistula survivors through a narrative inquiry approach at a repair centre in North-central Nigeria. Using structural violence as a lens, it describes the role of social, political and health systems in the inequitable access to care for women. For women opting for home births, preference for home delivery was mainly due to lack of finances, poor health systems and cultural practices. Rural location inhibited access as, women seeking facility delivery faced transfer delays to referral centres when complications developed. Inequitable maternal health services in rural locations in Nigeria are inherently linked to access to health care; and these contribute to the increased incidences of fistulae. Structural intervention is a health policy priority to address poor health systems and achieve universal health coverage to address maternal health issues in Nigeria.

KEYWORDS: word; obstetric fistula, structural violence, health systems, maternal health, narrative analysis, Nigeria

This is the peer reviewed version of the following article: Degge, HM, Laurenson, M, Dumbili, EW, Hayter, M. Insights from birthing experiences of fistula survivors in North-central Nigeria: Interplay of structural violence. Nurs Inq. 2020; 00:e12377, which has been published in final form at [ https://doi.org/10.1111/nin.12377. This article may be used for non-commercial purposes in accordance with Wiley Terms and Conditions for self-archiving. 


\section{INTRODUCTION}

Obstetric Fistula is an abnormal opening between the vagina and rectum resulting from prolonged and obstructed labour that can cause substantial, long term physical and psychological harm to the woman (Bangser, 2006; Wall 2006). The most common cause of fistula in developing countries is due to the obstruction of labour and delayed delivery (Wall, 2006). The inability of a woman to deliver her baby through the birth canal is caused by a discrepancy in the available space in the pelvic region and the foetal size or when the foetus' head or body is too big to pass through the mother's pelvis opening (Abrams, 2012; L. Lewis Wall, 2006). The obstruction leads to a prolonged pressured contact of the foetal head in the birth canal area, causing a loss of blood flow to the soft tissues of the woman's bladder, vagina and rectum (Arrowsmith, Hamlin, \& Wall, 1996; L. Lewis Wall, 2012).

Consequently, ischaemic injury leads to massive tissue necrosis in the woman's pelvis, which results in the fistula being formed (L. Lewis Wall, 2006).

Numerous studies have described women with obstetric fistula, as within the age range of 9 to 65 years, with the mean age usually less than 20 years (Alio et al., 2011; Landry et al., 2013; Lengmang \& Degge, 2017; Melah, 2007; Muleta, Fantahun, Tafesse, Hamlin, \& Kennedy, 2007; Tebeu et al., 2012; L. Wall, Karshima, Kirschner, \& Arrowsmith, 2004). It is also most common among the primiparous, accounting for the majority as compared to multiparous women (Alio et al., 2011; Lengmang \& Degge, 2017; Muleta et al., 2007; Tebeu et al., 2012; L. Wall et al., 2004). The outcome of obstructed delivery usually is stillbirth (Muleta et al., 2007; Tebeu et al., 2012; L. Wall et al., 2004). Women are reported to have low educational background with poor socioeconomic status (Landry et al., 2013; L. T. Mselle, Moland, Evjen-Olsen, Mvungi, \& Kohi, 2011; Muleta et al., 2007; L. Wall et al., 2004). Furthermore, the place of residence is usually rural (Alio et al., 2011; Landry et al., 2013; Melah, 2007; Muleta et al., 2007; L. Wall et al., 2004). 
One of the major reasons for fistula formation is a delay in care or treatment once labour has commenced. This delay is often related to three issues. 1. Delay in taking decision to seek care, 2. Delay in arriving at the health facility. 3. Delay in obtaining the required intervention at the facility (Thaddeus \& Maine, 1994; L. L Wall, 2009). Delay one is often attributed to women's lack of decision making power influenced by their low socioeconomic status and their financial capacity to pay for maternal health services (Kaplan et al., 2017; National Bureau of Economic Research, 2010; Onolemhemhen, 1999; Phillips, Ononokpono, \& Udofia, 2016). Additionally, spousal consent was required to seek care or it was traditional practice to have child delivery at home (Kaplan et al., 2017; L. T. Mselle, Kohi, Mvungi, Evjen-Olsen, \& Moland, 2011; Onolemhemhen, 1999; L. Wall et al., 2004). Many affected women lived in remote villages, and experienced transportation difficulties because of the distance to a health facility, bad roads, lack of a vehicle, or a lack of funds to pay transport costs (Maggie Bangser et al., 2011; Kaplan et al., 2017; Landry et al., 2013; L. T. Mselle, Kohi, et al., 2011; Nathan, Rochat, Grigorescu, \& Banks, 2009; Roka et al., 2013; L. Wall et al., 2004). Women also reported a further waiting period on arrival at health facilities, contributing to the third delay in necessary interventions. The delay at some facilities could also be attributed to unsupportive attitudes of health professionals both at pre-natal or during labour (L. Mselle \& Kohi, 2015; Nathan et al., 2009; Phillips et al., 2016). Additionally, poor referral protocols in transferring care for specialised attention were reported by women (L. T. Mselle, Kohi, et al., 2011; Roka et al., 2013). Further causes of delay include the absence of skilled birth attendants (SBA) and the lack of equipped facilities in rural settings to provide timely maternal health services (Maggie Bangser et al., 2011; de Bernis, 2007; L. T. Mselle, Kohi, et al., 2011; Phillips et al., 2016). An added concern was the absence of doctors in the public sector provision as some worked in private practice (Phillips et al., 2016). Sometimes, even when the facilities are available, the issue of affordability of services still serves as a 
hindrance to access (Phillips et al., 2016; L. L Wall, 2009).

\subsection{Structural violence and maternal health}

The concept of 'structural violence' is a way of describing social organisations that place individuals and populations in harm's way (Farmer, Nizeye, Stulac, \& Keshavjee, 2006; Galtung, 1969). The organisations are 'structural' because they are entrenched in the political and economic structure of our social world. Galtung (1969) describes violence as when human beings are being influenced so that their actual somatic and mental realizations are below their potential realisation, and this particularly is more so when the actual is avoidable. For instance, during the Neolithic era, 30 years of life expectancy was not a form of violence, but in the current dispensation, a life expectancy of 30 years either as a result of war or social injustice can be considered violent (Galtung 1969). Despite the global improvement to access to maternal health services, inequalities persist country by country, and within country between income group and geographical region (WHO, 2015). The inequalities reflected as poor health outcomes and low health intervention coverage for the poorest, and the least educated women and children who lived in rural areas (WHO, 2015). The United Nation's Maternal Mortality estimations in 2017, showed that Sub-Saharan Africa was the only region with very high Maternal Mortality Ratio, estimated at 542 (UI 498 to 649). In this region, the lifetime risk of maternal death was 1 in 37, as against 1 in 7800 in Australia and New Zealand (WHO, 2019).

Obstetric fistula is usually used as a "marker of overall maternal health" in a country (Roush et al, 2012: 788) because the underlying socio-cultural factors that contribute to fistula formation are also responsible for most of maternal deaths and morbidities (M. Bangser, 2007; Roush, Kurth, Hutchinson, \& Van Devanter, 2012). Unequal power distribution, which invariably leads to unequal opportunities in life, is 'violence' built into a structure. Therefore, 
our study through the voices of fistula survivors' birthing experiences provides a nuanced account of the structural elements surrounding a maternal morbidity. The experience of living with fistula within the social structures impacts every sphere of women's life and relationship, resulting in identity reconstructions (H. M. Degge, Laurenson, Dumbili, \& Hayter, 2020). Obstetric fistula is a public health concern in Nigeria. The country's contribution to the global burden is estimated to be $15 \%(\mathrm{FMoH}, 2018)$. The only treatment when labour becomes obstructed is C- section. Hence, the study will explore the index birthing circumstances. Using the structural violence concept, this study examines the social structures surrounding the formation of obstetric fistula among women. This understanding helps identify issues that are beyond the control of the woman and which require structural interventions to alleviate them.

\section{STUDY DESIGN AND METHODOLOGY}

A narrative inquiry methodology was used for this study. Narrative inquiry is grounded on the notion that people 'live storied lives'; and telling helps them to understand and subsequently generate meaning to it (Steinmetz, 1992). Similarly, narrative inquiry has the ability to depict the beginning, central and end, when describing a change (Steinmetz, 1992). It illustrates a serial pattern of events that happens over time with a cause and effect relationship (Steinmetz, 1992, p. 497). Our study, therefore, focused on gathering and interpreting the stories of fistula survivors at a fistula repair centre in North-central Nigeria between February and April 2016.

\subsection{Participants}

Using purposive sampling, we recruited women that fitted the inclusion criteria. This included women who were diagnosed and had undergone treatment for obstetric fistula (including rehabilitation) and had returned to living in the community for one year or more, 
and thus, identified as being able to answer the research question. In qualitative research, purposive sampling is used to identify and select information related to the phenomenon of interest (Creswell, 2007; Palinkas et al., 2015). Of twenty participants identified through hospital records and snowballing, 15 that met the inclusion criteria were recruited.

Participants were aged 14 - 42 years at the time of fistula development. Six women had completed primary education, four had secondary education, and one had Koranic education, while three had no form of education. At the time of fistula development, seven women were subsistence farmers, seven had no form of occupation, while one was a student in secondary school. For nine of the women, fistula occurred at the first delivery, while for the remaining six, it occurred between the second and fifth deliveries. Only two live births were recorded; the remaining 13 women had stillbirths. Further details are provided in Table 1.

Ethical approval was obtained from the Faculty of Health Sciences, University of Hull, United Kingdom and Bingham University Teaching Hospital, Jos, Nigeria. Participants received information (in their native Hausa language) about the study's purpose and their right to participate or withdraw and signed/thumbed printed a consent form. Participants have been identified with pseudonyms.

\subsection{Data collection and Analysis}

Interviews were conducted in a quiet room at the repair centre, using the local Hausa language by the first author (who is fluent in Hausa language) assisted by a research assistant. Participants had between 2-4 interviews each, with a mean length of 114 minutes. An episodic narrative interviewing method (Flick, 2000) generated data. Participants were asked to tell their story regarding their experiences with living with fistula. An interview guide served as prompts to explore specific episodes relating to the research objectives that participants might not have mentioned. Audio recordings were transcribed and translated by a 
native speaker. Comparisons were made between the transcriptions and the researchers' raw data field notes. Equally, translated transcripts were reviewed by listening repeatedly to the recordings by the first author with another native speaker carrying out a back translation of a sample of transcripts. All the transcripts were anonymized.

As a narrative inquiry approach, data analysis was carried out using Emden's (1997) 2-path procedure of core story creation, and emplotment for narrative analysis. The emplotment process identified three main sets of events (plots) that were common to all stories. The plot focused on in this article is the 'fistula ordeal' plot, and this explored the story of women's birthing experiences. The text analysis procedure involved comparing and contrasting the individual textual locations within the narrative constructions (Flick, 2014).

\section{FINDINGS}

The stories on the birthing process provided an insight into what eventually resulted in the fistula formation. In the sequence of events in the narratives, the focal actor, the woman, became embroiled in life-changing events where various issues considered as signposts were highlighted, and these issues demonstrated the role of various influences. The influencers in this context were either persons, or circumstances, or structures considered to have had a significant impact in the fistula formation. Three main interrelated influencers identified below were: influence of others, geographical location, transport, and a poor health system.

\subsection{Influence of 'Others' as Structural Violence}

From the narratives, women, even though they were the focal actors, appeared to be passive participants in the birthing process. The 'others' in the stories were persons that had an impact upon the process and outcome of birthing experience, and they were family members and birth attendants. The most prominent 'others' appear to be the family members: namely, mothers/mother-in-law or grandmothers, who appeared to be the traditional key players as females in birthing issues. Mothers/mothers-in-law or grandmother determined how and 
where birthing took place. For instance, their influence was obvious from the pregnancy period when issues surrounding where delivery should be, were decided without consideration to the woman's opinion, as demonstrated in Laila's story:

'I used to see a doctor (ANC) and the doctor told me that the child was too big, and I need to be taken to the hospital when it is time for me to deliver. However, because we have our culture like that of the Fulani, my parents came and took me from [name of city] where we were staying to the village to deliver ... '(Laila, 37yrs)

In the narratives, the preference for home delivery was influenced by cultural norms or financial limitations. In women's narratives, mother/mother-in-law or grandmothers were named as enforcers of cultural norms concerning childbirth. They also were responsible for decisions concerning seeking care during the birthing process when labour was not progressing successfully. Additionally, financial limitation was another strong reason influencing the preference for home delivery by 'others', especially because medical expenses are paid by users. This, therefore, limited access to health services. The 'others' were referred to as 'they' in women's narratives:

I couldn't take myself; 'they' were the ones to take me... but there was no money, so they couldn't take me to the hospital when labour started (Chundung, 52yrs)

As a result of these influences, home delivery was the choice. Family members or birth attendants attended to women in labour; this could be traditional birth attendants (TBAs) or 'skilled birth' attendants (SBAs). The deliveries took place either in women's home or in the birth attendant's home. The birth attendants could employ diverse materials to aid labour from use of traditional remedies to orthodox medicine. Women described the variety of assistance provided during their labour experiences, all with no positive outcome:

'They decided to let them try the local way, "she will deliver" ... so they brought a freshly hatched chick and added this to a concoction so... that I will deliver right 
away, but no way. They put a big wooden stick (used for stirring 'tuwo'- a local food) in my mouth and said that is how it is done. I will deliver right away... I could not urinate, and they even pounded and mixed a slimy vegetable and started pouring this into in my front side to force the head of the baby out...' (Maryamu, 38 yrs)

The professional identity of SBAs called to assist in home delivery was unknown. Women referred to them as 'doctors' or 'persons that worked in hospital' but could not specifically identify whether they were midwives or medical doctors:

'An uncle' that was working in one clinic, when I started labour, he said he is going to try but if he fails, then we can go to the hospital. I am not sure whether he is a nurse or doctor... he works in the hospital' (Susan, 37 yrs)

The labour at home before seeking medical assistance was between 1- 5 days. When all efforts failed in home delivery, the decision to seek care can be initiated by the birth attendant or by family members and not the woman. For births assisted by SBAs, the decision for referral took place approximately after one day of labour:

'The man (who works in hospital) ... tried all night and he gave me injection and IVF...but nothing happened... in the morning when he couldn't handle it, I was transferred to P Hospital where I had C/S' (Leah, 33 yrs).

'I was suffering... that night the pain became unbearable and I cried out, "oh my God! I am dead!" My mother joined me and started crying. After trying and trying, the 'doctor' decided that I should be taken to the hospital...they took me [to the hospital] in the morning' (Susan, $37 \mathrm{yrs}$ ).

The decision to seek institutional attention for women assisted by TBAs occurred after longer periods of days, between two to five days, and was often taken by another family member pressurising the 'influential' person to see reason. Seeking care for one woman resulted after the intervention of the natal family, another woman lamented/reasoned that the 
absence of her mother contributed to her ordeal. The TBAs undoubtedly did not possess the ability to detect danger signs indicative of complications. The TBAs instead adhered to their usual manner of practice regardless, being oblivious of the outcome of their continued delay to seek medical care:

I spent three days at home in labour before I was taken to the hospital in the village. I think she (mother) might have stopped the woman that they called from pushing her hand inside me, because I think that is one of the reasons, I started leaking urine. She kept poking her hands inside... (Deborah, 32yrs)

It is important to note here that the narratives on what transpired provides avenue of doubts on the professional competence of the birth attendants in identifying danger signs during labour indicating the need for prompt emergency obstetric assistance. Equally, narratives on deliveries in homes attended by 'skilled' attendants create a picture of the kind of practice in the rural areas. It is crucial to note that in both TBA or SBA assisted deliveries, the outcome was poor, 13 out of the 15 participants had stillbirths.

\subsection{Geographical Location and Transport Issues as Structural Violence}

All the women except one lived in rural locations in the northern parts of Nigeria (See Table 1- Demographic information). However, for the only woman who lived in the city, the incident occurred in a rural location in North-west Nigeria. As earlier mentioned, this was due to their cultural practices surrounding child delivery in her natal home. On the whole, living in the rural geographical location meant either the absence of hospitals or the presence of hospitals with no capacity to provide the required assistance. Furthermore, due to geographical remoteness, transportation was an issue, hence some women experienced further delays in receiving the necessary interventions. For instance, it is either that a village had 'only one motor vehicle' or that women had to be transported by some hazardous means 
like motor bikes. In some cases, a wheelbarrow was used:

Our village is off the road; there is only one vehicle in the village. They went to get the vehicle, but we were told that the driver has gone out with passengers. He did not come back until around 9:30 PM. That was when they took me to the clinic in our village which was very small... They told us that I cannot give birth there, that I should be taken to a bigger hospital (city name provided) (Laila, $37 \mathrm{yrs}$ ).

...since we are in the village (there is no hospital at that time), there was no car. So, they took me with the wheelbarrow to (city name provided), where the hospital in my state [province] is (Maryamu, $38 \mathrm{yrs}$ )

The influence of geographical location on fistula formation was made more apparent and significant with women who sought immediate institutional delivery at the onset of labour. These women experienced serious delays in accessing care despite efforts made to seek care early. Three out of the fifteen women reported going into the hospital, at the onset of labour. Nevertheless, even in these cases, women again had to face the additional hurdles of moving from one hospital to another and only finally received the required emergency obstetric care (EmOC) at an urban hospital:

'I started feeling pains in my stomach, so I went to the hospital that same day. When I entered the hospital, they said, "See, the boy is coming out". The boy started coming out head first, that was around 4 p.m. When the head came out, it stopped there... it neither came out nor went back in. There was no doctor in that hospital... The whole nurses spent that night on me... They asked us to go to the hospital in town after this... Our road was bad then, so they put me on a motorcycle' (Rita, 38 yrs)

'I started labour at around 10pm... I was first taken to the (named provided) hospital when they couldn't handle it, I was moved to (named provided) hospital and when that one couldn't work too, I was moved to the specialist hospital (urban location). Many doctors were called but couldn't deliver me, so I was taken to the theatre...' (Ruth, 30 yrs)

\subsection{Poor Healthcare System as Structural violence}

Related to the above, another influence on fistula formation was the issue of poor healthcare 
systems in rural facilities. In the context of these narratives, a poor healthcare system was considered with reference to ease of immediate access to required care on the arrival at health facility. Other related factors include the availability of staff, and the capacity (infrastructure) to provide EmOC at health facilities to address the obstructed labour, and affordability of the services. Interestingly, only one woman received immediate EmOC upon arrival at a health facility. This was provided after travelling to an urban health facility. However, for the majority, there were further delays even at the health facility. The reasons for these delays were different for each woman. In addition to those described above, strike action by hospital health workers, and arrival on a non-working day (weekend) were reported. Narratives described incidences that appear to be unwholesome practices. A woman narrated a tale of negligence, where health workers delayed calling for the doctor for 10 hours despite being instructed to do so after 30 minutes. There were also tales of procedures carried out in evacuating the baby that women believed were the causes of their fistula developing. Women described what transpired:

'It was then a nurse in the hospital said she was going to sit on me here (touched her chest) to make the baby come out. I told her, “...you want to kill me”. She said it's because of my stubbornness that something bad will happen to me. The next thing I was looking at the machine, lying down... I heard the noise of a machine that they used to pull out the baby...grrrrrrrrrrrrrrrl... What I knew next was urine...and stool'. (Maryamu, 38 yrs)

'When we got to the hospital, the doctor examined me and instructed the nurses that if I didn't deliver in thirty minutes, they should call him...We got to the hospital around ten in the morning and we were there till 8pm in the night before they called the doctor. The doctor was furious; he told them that they have killed me, saying that his instruction was if I didn't deliver in thirty minutes, they should call him. He told them to take me to the theatre, but they kept pushing the responsibility to each other, so I walked gently to the theatre where I had surgery (Susan, $37 \mathrm{yrs}$ ). 
These highlighted issues cast doubt on equitable health service provision in the rural areas.

\section{DISCUSSION}

The findings of this study, which drew on structural violence, have exposed the interplay of the social arrangements that led to the delays of women's deliveries. Previous research shows that structural violence is the major cause of premature deaths and disabilities among the vulnerable population (Farmer et al., 2006). The failings of the society at the family, community and political levels highlight the structural violence. Typically, structural violence does not affect the perpetrators of the inequalities. As a functionality of the social systems, it is entrenched in the daily activities (Basnyat, 2017), which was evidenced in the study. The influencers of fistula formation in this study clearly support discourses that a chaotic socioeconomic and political system prevails in societies where obstetric fistula occurs (Wall, 2012). The narratives in this study reflect the structural violence that contributes to the "differential risks" that led to fistula formation and resonates with the work of Kleinman and Seeman (2003:232). The major inherent risks of womanhood in a rural setting magnified their powerlessness. As was noted in this study, the outcome of delivery usually is stillbirth (Muleta et al., 2007; Tebeu et al., 2012; L. Wall et al., 2004). Hence rightly a case of "double burden of tragedy" (Ahmed, Anastasi, \& Laski, 2016) e90). Even though the attendant consequences of a still birth delivery were not explored in our study, in a society that places high premium on motherhood, the loss of a child at birth magnifies women's powerlessness.

In the narratives, women appeared to be passive participants in the birthing experiences that culminated in fistula formation. Entrenched in the everyday practices, the experiences of these women somewhat expose the sociocultural dimension of structural violence. The influence of 'others' in the narratives identified as family members, TBAs and SBAs that presided over the birthing process is suggestive of women's lack of self-autonomy to 
influence seeking health care, and this caused the first two delays. Roush et al. (2012) argued that the typical characteristics of women that develop obstetric fistula place them in the position of gender power imbalance, which contributed to fistula formation. The additional disadvantaging factor which describes the economic structure of structural violence was that women in this study were all from a low socioeconomic class. Additionally, they resided in the rural locations in Northern Nigeria at the time of incidence. Prior studies show women are typically young, poor with low educational qualification and of the rural location, hence they lack the power to challenge norms and negotiate reproductive behaviour (Barageine, Tumwesigye, Byamugisha, Almroth, \& Faxelid, 2014; Hamed, Ahlberg, \& Trenholm, 2017; L. Wall et al., 2004). Contrary to prior studies, the voices of males as decision-makers were noticeably absent in our study. However, it might be erroneous to assume that males are not major influencers. But the findings highlight that males might not be the only significant 'others' during childbirth. To examine this further, a qualitative study exploring the role of men in decision making during childbirth is recommended in this setting.

Education, socio-economic status and location are strongly associated with utilisation of maternal health services. Women of low education with poor socio-economic status living in rural locations were least likely to have delivery assisted by SBAs in Nigeria (Stella Babalola \& Adesegun Fatusi, 2009; NPC \& ICF, 2014). In this study, women who had TBAs attending as well as some women who had births assisted by 'SBA' at home attributed financial constraints as the cause. The birthing experiences of these women further exposed the contributions of financial barriers to the inequitable access to maternal health care in Nigeria, particularly in rural health facilities. This economic dimension of structural violence has a strong link with political failings. In earlier times, services in public hospitals were free or incurred minimal charges, but Structural Adjustment Policy (SAP) led to the introduction of user fees by the government (Wang'ombe, 1995). This allegedly contributed to limiting 
health care access to the poor (Heller \& Hannig, 2017; Leach, 2015; Peters et al., 2008; Sparr, 1994). Interestingly, the foundation for the poor health system structure has been equally traced to colonization and post-colonization, which incapacitated local economies and public services (Heller \& Hannig, 2017; Kim, Millen, \& Irwin, 2000; Potter, 2004). The top-down health system model in practice in former colonies is a legacy of colonization. This model emphasised curative rather than preventive care and the location of specialised care only in large cities. This laid the foundation for inequitable health access for rural and poverty-stricken geographical areas (Inem, 2014; Potter, 2004; Scott-Emuakpor, 2010). As evidenced in this study, Romanzi, Meara, Anastasi, and Knutsson (2019) assert that most maternity facilities are not only too far to walk to, but also not worth walking to in the first place.

Nigeria ranks low in health services provisions, and this was evidenced in our study. In 2017, Nigeria (23\%) and India (12\%) are the largest contributors to maternal deaths in the world (WHO, 2019). Maternal deaths have been depicted as the "tip of the iceberg and maternal morbidity as the base" (Firoz et al., 2013, p.794), for every woman that dies, 20 to 30 women suffer pregnancy-related acute or chronic morbidities (Firoz et al., 2013; Rosenfield, Min, \& Freedman, 2007). One reason that has been argued to be contributory is the low government contribution to health expenditure. In 2015, the health expenditure as a total of gross domestic product (GDP) was 3.6\% (WHO, 2017). The low level of government funding translates into great reliance on user fees to fund health care, hence limiting the access to care for the poor (FMoH, 2009; Kress, Su, \& Wang, 2016). Hence, Nigerians mostly finance their healthcare with 'out-of-pocket-payments' (OOP) as was demonstrated in this study. For example, in 2015 , the private out-of-pocket expenditure in Nigeria was $72 \%$ of the current health expenditure (WHO, 2017). Furthermore, due to government neglect, political corruption and poor funding of public healthcare infrastructure by the state and Federal 
governments in Nigeria, health workers often embark on protracted industrial actions, and this has dire consequences on patients (Oleribe et al., 2016).

Fistula formation occurred for nine women during the first delivery, while for six women, it was between the second to fifth deliveries. Hence, women were from all the reproductive life stages and so concurred with earlier studies (Hannah Mafo Degge, Hayter, \& Laurenson, 2017; Heller \& Hannig, 2017). This supports the arguments that since it happens to both younger and older women of any parity, lack of access to SBA and Emergency Obstetric Care (EmOC) appears to be the primary cause (Abrams, 2012; Maggie Bangser et al., 2011; Heller \& Hannig, 2017; Phillips et al., 2016). On the other hand, some studies have argued that early marriage and cultural practices that limit women's autonomy are underlying reasons for fistula development (Alio et al., 2011; Gebresilase, 2014; Melah, 2007; L. Wall et al., 2004). The higher than expected median age of first marriage among the participants might suggest the gradual impact of on-going campaigns to discourage early marriage and encourage the education of the females by the government of Nigeria in response to the MDG(WB, 2011). However, it is important to note here, that only one participant was from the Fulani ethnic group, particularly noted for early marriage custom. Therefore, further research is required to verify if there is a positive shift among the rural population with cultures of early marriage. Heller and Hannig (2017) argued that the focus on the pathology of culture by some authors is a diversionary distraction from the structural violence that led to fistula formation and how women negotiate the pathway of recovery from fistula. For instance, the United States has the highest teen pregnancy rates in the developed world (Guttmacher Institute, 2015). Heller and Hannig (2017) further argued that despite the United States' record of high teenage pregnancies, fistula occurrence is rare. Therefore, this pinpoints the issue of structural violence as opposed to cultural issues. Evidence from other countries, equally shows that maternal health issues among adolescent births are common 
among the populations with poorer access to high-quality maternity care (Nove, Matthews, Neal, \& Camacho, 2014).

Previous studies on fistula described preferences for home deliveries that were attended to by family or TBA. Our finding corroborates those of previous studies that reported lower facility delivery for women in Northern Nigeria (Stella. Babalola \& Adesegun Fatusi, 2009; Doctor, Radheshyam, E., Stephane, \& Tukur, 2011; Galadanci, Ejembi, Iliyasu, Alagh, \& Umar, 2007). However, in this study, interestingly, there were cases of women who had a home delivery being attended and/'helped' by an 'SBA', and this has not been previously reported. There was no evidence to show that the delivery services provided were under a coordinated maternal health management program. It is, therefore, important to investigate this new trend of home delivery assisted by the 'SBA' to examine any possible links with fistula development, to forestall further worsening of the case scenario. Additionally, the women who choose institutional delivery remained powerless because of their geographical location and the poor health care system in rural areas. As a structural violence case, concurring with other studies, fistula occurs only among women with low economic status who were unable to seek better care, hence, rightly so referred to as a ‘disease of poverty’ (Abrams 2012, p. 43).

As this was a small study, in one geographical area, the extent to which the findings are generalizable can be queried. However, qualitative studies are not intended to be completely generalizable but provide rich data that can inform thinking in relation to other settings and cultures - our study forms a starting point for others to base further research on thus building the field of knowledge incrementally (Elliott, 2005; Riessman, 2008)Furthermore, Thomas and Magilvy (2011) maintain that the qualitative researchers role is to provide a good description of participants' demographic and geographic details to improve transferability. Hence, the demographic details of the participants in this study will 
allow informed judgement on how the findings can be applied or interpreted in other settings and cultures (Marshall \& Rossman, 2011).

\section{CONCLUSION AND RECOMMENDATIONS}

This study using the structural violence concept has demonstrated the underlying trajectories that contributed to fistula formation: the failures of the social, political and health system to ensure equitable access to health care for all women. The study evidenced obstetric fistula, as a product of structural violence occurring in a country with a poor health system, resulting into the case of 'double burden tragedy'. While mostly associated with childbirth at an early age, our study supported the evidence that fistula could occur in any delivery when complications develop, especially where EmOC is unavailable. In addition, access to care has mainly been hampered by rural location, transport, and user fees. Financial constraints played a prominent role in limiting access to care. Interestingly, home deliveries assisted by SBA- a trend not earlier discussed in prior research, have been identified as potential for further research, due to its implication in this research in contributing to fistula development.

An emergency country-owned coordinated response to ensuring access to the provision of comprehensive emergency obstetric care to all women is crucial in eradicating fistula. Most importantly, generating political will and sustained commitment in Nigeria and countries where fistula remains an issue is suggested in redressing the chaos in the health system. We recommend that attention needs to be centred on addressing the inequitable access to maternal health in rural locations by the government. Additionally, we recommend the recognition of maternal morbidity, as a measurable indicator in addressing maternal health issues. Adopting this stance would boost the global accountability measure of maternal 
health. Attracting political priority by countries for addressing maternal health can only be achieved when maternal morbidities like fistula is put into consideration.

\section{ACKNOWLEDGMENT}

We acknowledge the courageous women that shared their stories

\section{Disclosure statement}

No potential conflict of interests was reported by the authors

\section{Funding details}

Nil 


\section{REFERENCES}

Abrams, P. (Ed.) (2012). Obstetric fistula in the developing world. An international consultation on vesicovaginal fistula. China: Societe Internationale d'Urologie.

Ahmed, S., Anastasi, E., \& Laski, L. (2016). Double burden of tragedy: stillbirth and obstetric fistula. Lancet Glob Health, 4(2), e80-82. doi:10.1016/s2214-109x(15)00290-9

Alio, A. P., Merrell, L., Roxburgh, K., Clayton, H. B., Marty, P. J., Bomboka, L., . . . Salihu, H. M. (2011). The psychosocial impact of vesico-vaginal fistula in Niger. Archives of gynecology and obstetrics, 284(2), 371-378. doi:10.1007/s00404-010-1652-5

Arrowsmith, S., Hamlin, E. C., \& Wall, L. L. (1996). Obstructed labor injury complex: Obstetric fistula formation and the multifaceted morbidity of maternal birth trauma in the developing world. Obstetrical and Gynecological Survey, 51(9), 568-574. doi:10.1097/00006254-199609000-00024

Babalola, S., \& Fatusi, A. (2009). Determinants of use of maternal health services in Nigeria--looking beyond individual and household factors. BMC Pregnancy and Childbirth, 9(1), 43-43. doi:10.1186/1471-2393-9-43

Babalola, S., \& Fatusi, A. (2009). Determinants of use of maternal health services in Nigeria - looking beyond individual and household factors. BMC pregnancy and childbirth, 9(1), 43. doi:10.1186/1471-2393-9-43

Bangser, M. (2007). Strengthening public health priority-setting through research on fistula, maternal health, and health inequities. International Journal of Gynecology and Obstetrics, 99(1), S16-S20. doi:10.1016/j.ijgo.2007.06.016

Bangser, M., Mehta, M., Singer, J., Daly, C., Kamugumya, C., \& Mwangomale, A. (2011). Childbirth experiences of women with obstetric fistula in Tanzania and Uganda and their implications for fistula program development. International Urogynecology Journal, 22(1), 91-98. doi:10.1007/s00192-010-1236-8

Barageine, J. K., Tumwesigye, N. M., Byamugisha, J. K., Almroth, L., \& Faxelid, E. (2014). Risk factors for obstetric fistula in Western Uganda: a case control study. PloS one U6 -

ctx_ver $=Z 39.88-2004 \& c t x$ enc $=$ info $\% 3 \mathrm{Aofi} \% 2 \mathrm{Fenc} \% 3 \mathrm{AUTF}-8 \& \mathrm{rfr}$ id=info:sid/sum mon.serialssolutions.com\&rft_val_fmt=info:ofilfmt:kev:mtx:journal\&rft.genre $=$ articl e\&rft.atitle $=$ Risk + factors + for + obstetric + fistula $+i n+$ Western + Uganda $\% 3 A+a+$ case + control + study\&rft.jtitle $=$ PloS + one\&rft.au $=$ Barageine\%2C + Justus + Kafunjo\&rft.a $u=$ Tumwesigye $\% 2 C+$ Nazarius + Mbona\&rft.au $=$ Byamugisha $\% 2 C+$ Josaphat + K\&rft.a $u=$ Almroth $\% 2 C+$ Lars\&rft.date $=2014 \& r f t$.eissn $=1932-6203 \& r f t$. volume $=9 \& r f t$. issue $=11 \& r f t$.spage $=e 112299 \& r f t$ id $=$ info:pmid $/ 25401756 \& r f t$.externalDocID $=25401756$ \&paramdict=en-US U7 - Journal Article U8 -

FETCH-LOGICAL-c686-67dd07aca7fd36aa3bff730bd18a365e31b8f7d2b329a63fe80 e92132aflcfba3, 9(11), e112299. doi:10.1371/journal.pone.0112299

Basnyat, I. (2017). Structural Violence in Health Care:Lived Experience of Street-Based Female Commercial Sex Workers in Kathmandu. Qualitative Health Research, 27(2), 191-203. doi:10.1177/1049732315601665

Creswell, J. W. (2007). Qualitative inquiry \& research design : choosing among five approaches (Third edition. ed.).

de Bernis, L. (2007). Obstetric fistula: Guiding principles for clinical management and programme development, a new WHO guideline. International Journal of Gynecology and Obstetrics, 99(1), S117-S121. doi:10.1016/j.ijgo.2007.06.032 
Degge, H. M., Hayter, M., \& Laurenson, M. (2017). An integrative review on women living with obstetric fistula and after treatment experiences. Journal of Clinical Nursing, 26(11-12), 1445-1457. doi:10.1111/jocn. 13590

Degge, H. M., Laurenson, M., Dumbili, E. W., \& Hayter, M. (2020). Reflections on Identity: Narratives of Obstetric Fistula Survivors in North Central Nigeria. Qual Health Res, 30(3), 366-379. doi:10.1177/1049732319877855

Doctor, H. V., Radheshyam, B., E., F. S., Stephane, H., \& Tukur, D. (2011). Northern Nigeria Maternal, Newborn and Child Health Programme: Selected Analyses from Population-Based Baseline Survey. The Open Demography Journal(4), 11-21.

Elliott, J. (2005). Using narrative in social research : qualitative and quantitative approaches. London :: SAGE.

Farmer, P. E., Nizeye, B., Stulac, S., \& Keshavjee, S. (2006). Structural Violence and Clinical Medicine. PLoS Medicine, 3(10), e449. doi:10.1371/journal.pmed.0030449

Firoz, T., Chou, D., von Dadelszen, P., Agrawal, P., Vanderkruik, R., Tunçalp, O., . . . for the Maternal Morbidity Working, G. (2013). Measuring maternal health: focus on maternal morbidity. Bulletin of the World Health Organization, 91(10), 794-796. doi:10.2471/BLT.13.117564

Flick, U. (2000). Qualitative Researching with Text, Image and Sound. In. London: SAGE Publications Ltd.

FMoH. (2009). The National Strategic Health Development Plan Framework (2009- 2015). Abuja: Nigeria: Federal Ministry of Health

FMoH. (2018). Strategic Plan for the Elimination of Obstetric Fistula in Nigeria 2018-2022. Retrieved from Abuja: Nigeria ( In press):

Galadanci, H., Ejembi, C., Iliyasu, Z., Alagh, B., \& Umar, U. (2007). Maternal health in Northern Nigeria-a far cry from ideal. 114(4), 448-452.

doi:10.1111/j.1471-0528.2007.01229.x

Galtung, J. (1969). Violence, Peace, and Peace Research. Journal of Peace Research, 6(3), 167-191.

Gebresilase, Y. T. (2014). A qualitative study of the experience of obstetric fistula survivors in Addis Ababa, Ethiopia. International journal of women's health U6 -

ctx_ver $=Z 39.88-2004 \& c t x \_$enc $=$info $\% 3 \mathrm{Aofi} \% 2 \mathrm{Fenc} \% 3 \mathrm{AUTF}-8 \& \mathrm{rfr}$ id $=$ info:sid/sum mon.serialssolutions.com\&rft_val_fmt $=$ info:ofilfmt:kev:mtx:journal\&rft.genre $=$ articl $e \& r f$ tatitle $=A+$ qualitative + study + of + the + experience $+o f+$ obstetric + fistula + survivo $r s+i n+$ Addis + Ababa\%2C + Ethiopia\& $r f t$.jtitle $=$ International + journal + of + women $\% 2$ $7 s+$ health\&rft.au $=$ Gebresilase $\% 2 C+$ Yenenesh + Tadesse\&rft.date $=2014 \& r f t . e i s s n=1$ $179-1411 \& r f t$.volume $=6 \& r f t$.spage $=1033 \& r f t$ id $=$ info:pmid $/ 25525395 \& r f t$.external DocID=25525395\&paramdict $=$ en-US U7 - Journal Article U8 FETCH-pubmed_primary_255253953, 6, 1033.

Hamed, S., Ahlberg, B.-M., \& Trenholm, J. (2017). Powerlessness, Normalization, and Resistance: A Foucauldian Discourse Analysis of Women's Narratives On Obstetric Fistula in Eastern Sudan. Qualitative Health Research, 27(12), 1828-1841. doi:10.1177/1049732317720423

Heller, A., \& Hannig, A. (2017). Unsettling the fistula narrative: cultural pathology, biomedical redemption, and inequities of health access in Niger and Ethiopia. Anthropology \& Medicine, 24(1), 81-95. doi:10.1080/13648470.2016.1249252

Inem, V. (2014). The Challenges of Health System in Developing Countries. In A. B. Chater, J. Rourke, I. D. Couper, P. P. Strasser, \& S. Reid (Eds.), WONCA Rural Medical Education Guidebook: World Organisation of Family Doctors (WONCA): WONCA Working Policy on Rural Practice. Retrieved from www.globalfamilydoctor.com. 
Kaplan, J. A., Kandodo, J., Sclafani, J., Raine, S., Blumenthal-Barby, J., Norris, A., . . . Chunda, R. (2017). An investigation of the relationship between autonomy, childbirth practices, and obstetric fistula among women in rural Lilongwe District, Malawi. BMC International Health and Human Rights, 17, 17. doi:10.1186/s12914-017-0125-3

Kim, J., Millen, J., \& Irwin, A. (2000). Dying for growth: Global inequity and the health of the poor. USA: Common Courage Press.

Kress, D. H., Su, Y., \& Wang, H. (2016). Assessment of Primary Health Care System Performance in Nigeria: Using the Primary Health Care Performance Indicator Conceptual Framework. Health Systems \& Reform, 2(4), 302-318. doi:10.1080/23288604.2016.1234861

Landry, E., Inoussa, M., Kanoma, B., Lynch, M., Mussell, F., Podder, D. C., . . Idris, S. a. (2013). Profiles and experiences of women undergoing genital fistula repair: findings from five countries. Global public health, 8(8), 926-942. doi:10.1080/17441692.2013.824018

Leach, M. (2015). The Ebola Crisis and Post-2015 Development. Journal of International Development, 27(6), 816-834. doi:10.1002/jid.3112

Lengmang, S. J., \& Degge, H. (2017). Characteristics of Obstetric Fistula in Kaduna Metropolis. Open Journal of Obstetrics and Gynecology, Vol.07No.07, 8. doi:10.4236/ojog.2017.77074

Marshall, C., \& Rossman, G. B. (2011). Designing qualitative research (5th ed. ed.). Thousand Oaks, Calif. ;: Sage Publications.

Melah, G. S. (2007). Risk factors for obstetric fistulae in north-eastern Nigeria. Journal of Obstetrics \& Gynecology, 27(8), 819-823. doi:10.1080/01443610701709825

Mselle, L., \& Kohi, T. (2015). Perceived Health System Causes of Obstetric Fistula from Accounts of Affected Women in Rural Tanzania: A qualitative study. Afr J Reprod Health, 19(1), 124-132.

Mselle, L. T., Kohi, T. W., Mvungi, A., Evjen-Olsen, B., \& Moland, K. M. (2011). Waiting for attention and care: birthing accounts of women in rural Tanzania who developed obstetric fistula as an outcome of labour. BMC pregnancy and childbirth, 11(75). doi:10.1186/1471-2393-11-75

Mselle, L. T., Moland, K. M., Evjen-Olsen, B., Mvungi, A., \& Kohi, T. W. (2011). "I am nothing": experiences of loss among women suffering from severe birth injuries in Tanzania. BMC women's health, 11(1), 49-49. doi:10.1186/1472-6874-11-49

Muleta, M., Fantahun, M., Tafesse, B., Hamlin, E. C., \& Kennedy, R. C. (2007). Obstetric fistula in rural Ethiopia. East Afr Med J, 84.

Nathan, L. M., Rochat, C. H., Grigorescu, B., \& Banks, E. (2009). Obstetric fistulae in West Africa: patient perspectives. Am J Obstet Gynecol, 200(5), e40-e42. doi:10.1016/j.ajog.2008.10.014

National Bureau of Economic Research, I. (2010). Business Cycle Dating Committee. Retrieved from http://www.nber.org/cycles.html

Nove, A., Matthews, Z., Neal, S., \& Camacho, A. V. (2014). Maternal mortality in adolescents compared with women of other ages: evidence from 144 countries. The Lancet Global Health, 2(3), e155-e164. doi:10.1016/S2214-109X(13)70179-7

NPC, \& ICF. (2014). Nigeria Demographic and Health Survey 2013. In. Abuja: Nigeria Maryland: USA: National Population Commission.

Onolemhemhen, D. O., C.C. Ekwempu. (1999). An Investigation of Sociomedical Risk Factors Associated with Vaginal Fistula in Northern Nigeria. Women \& Health, 28(3), 103-116. doi:10.1300/J013v28n03_07 
Palinkas, L. A., Horwitz, S. M., Green, C. A., Wisdom, J. P., Duan, N., \& Hoagwood, K. (2015). Purposeful sampling for qualitative data collection and analysis in mixed method implementation research. Administration and policy in mental health, 42(5), 533-544. doi:10.1007/s10488-013-0528-y

Peters, D. H., Garg, A., Bloom, G., Walker, D. G., Brieger, W. R., \& Hafizur Rahman, M. (2008). Poverty and Access to Health Care in Developing Countries. Annals of the New York Academy of Sciences, 1136(1), 161-171. doi:10.1196/annals.1425.011

Phillips, B. S., Ononokpono, D. N., \& Udofia, N. W. (2016). Complicating causality: patient and professional perspectives on obstetric fistula in Nigeria. Culture, Health \& Sexuality, 18(9), 996-1009. doi:10.1080/13691058.2016.1148198

Potter, R. B. (Ed.) (2004). Geographies of development. Harlow Pearson/Prentice Hall.

Riessman, C. K. (2008). Narrative methods for the human sciences. London :: Sage.

Roka, Z. G., Akech, M., Wanzala, P., Omolo, J., Gitta, S., \& Waiswa, P. (2013). Factors associated with obstetric fistulae occurrence among patients attending selected hospitals in Kenya, 2010: a case control study. BMC pregnancy and childbirth, 13(56).

Romanzi, L., Meara, J. G., Anastasi, E., \& Knutsson, A. T. (2019). Meeting the SDG challenge to end fistula and preventable childbirth-related morbidity and mortality. The Lancet Global Health, 7(7), e835-e836. doi:10.1016/S2214-109X(19)30198-6

Rosenfield, A., Min, C. J., \& Freedman, L. P. (2007). Making Motherhood Safe in Developing Countries. The New England Journal of Medicine, 356(14), 1395-1397. doi:10.1056/NEJMp078026

Roush, K., Kurth, A., Hutchinson, M. K., \& Van Devanter, N. (2012). Obstetric fistula: what about gender power? Health care for women international, 33(9), 787-798. doi:10.1080/07399332.2011.645964

Scott-Emuakpor, A. (2010). The evolution of health care systems in Nigeria: Which way forward in the twenty-first century. Nigerian Medical Journal, 51(2), 53-65.

Sparr, P. (Ed.) (1994). Mortgaging women's lives: feminist critiques of structural adjustment London: UK: United Nations.

Steinmetz, G. (1992). Reflections on the Role of Social Narratives in Working-Class Formation: Narrative Theory in the Social Sciences. Social Science History, 16(3), 489-516. doi:10.2307/1171393

Tebeu, P. M., Fomulu, J. N., Khaddaj, S., De Bernis, L., Delvaux, T., \& Rochat, C. H. (2012). Risk factors for obstetric fistula: A clinical review. International Urogynecology Journal and Pelvic Floor Dysfunction, 23(4), 387-394. doi:10.1007/s00192-011-1622-x

Thaddeus, S., \& Maine, D. (1994). Too far to walk: Maternal mortality in context. Social Science \& Medicine, 38(8), 1091-1110. doi:http://dx.doi.org/10.1016/0277-9536(94)90226-7

Wall, L., Karshima, J. A., Kirschner, C., \& Arrowsmith, S. D. (2004). The obstetric vesicovaginal fistula: Characteristics of 899 patients from Jos, Nigeria. American Journal of Obstetrics and Gynecology, 190(4), 1011-1016. doi:10.1016/j.ajog.2004.02.007

Wall, L. L. (2006). Obstetric vesicovaginal fistula as an international public-health problem. The Lancet, 368(9542), 1201-1209. doi:10.1016/S0140-6736(06)69476-2

Wall, L. L. (2009). The Global Burden of Obstetric Fistula. In J. Ehiri (Ed.), Maternal and Child Health: Global Challenges, Programs and Policies (pp. 311-321). London: Springer. 
Wall, L. L. (2012). Overcoming phase 1 delays: the critical component of obstetric fistula prevention programs in resource-poor countries. BMC pregnancy and childbirth, 12(1), 68-68. doi:10.1186/1471-2393-12-68

Wang'ombe, J. (1995). Public health crises of cities in developing countries. Soc Sci Med, 41(6), 857-862.

WB. (2011). Nigeria Socioeconomic assessment. Retrieved from Washington, D.C:

WHO. (2017). Global Health Observatory data repository. Retrieved from http://apps.who.int/gho/data/node.main.HEALTHFINANCING?lang=en

WHO. (2019). Trends in maternal mortality 2000 to 2017: estimates by WHO, UNICEF, UNFPA, World Bank Group and the United Nations Population Division. In. Geneva: World Health Organization. 